Article

\title{
Heritage Portuguese and Heritage Polish in Contact with German: More Evidence on the Production of Objects
}

\author{
Esther Rinke $^{1, *}$, Cristina Flores ${ }^{2}\left(\mathbb{D}\right.$ and Aldona Sopata ${ }^{3} \mathbb{C}$ \\ 1 Institut für Romanische Sprachen und Literaturen, Goethe-Universität Frankfurt am Main, \\ 60629 Frankfurt am Main, Germany \\ 2 Centro de Estudos Humanísticos, Universidade do Minho, 4710-057 Braga, Portugal \\ 3 Faculty of Modern Languages and Literatures, Adam Mickiewicz University, 61874 Poznań, Poland \\ * Correspondence: Esther.Rinke@em.uni-frankfurt.de
}

Received: 9 June 2019; Accepted: 5 July 2019; Published: 10 July 2019

\begin{abstract}
This paper compares the production of different types of direct objects by Portuguese-German and Polish-German bilingual school-aged children in their heritage languages (HLs), Polish and European Portuguese (EP). Given that the two target languages display identical options of object realization, our main research question is whether the two HLs develop in a similar way in bilingual children. More precisely, we aim at investigating whether bilingual children acquiring Polish and EP are sensitive to accessibility and animacy when realizing a direct object in their HL. The results of a production experiment show that this is indeed the case and that the two groups of bilinguals do not differ from each other, although they may overgeneralize null objects or full noun phrases to some extent. We conclude that the bilingual acquisition of object realization is guided by the relevant properties in the target languages and is not influenced by the contact language, German.
\end{abstract}

Keywords: heritage speakers; Polish; European Portuguese; object realization; animacy; accessibility; clitic pronouns; null objects

\section{Introduction}

This paper addresses the linguistic competence of Portuguese-German and Polish-German bilingual primary school-aged children in their heritage language (HL), European Portuguese (EP) or Polish. The main focus lays on their production of referential expressions and their realization through different types of direct objects (definite noun phrases (NPs), clitic pronouns, null objects). The production (and comprehension) of referential expressions requires the acquisition of syntactic knowledge, namely the knowledge of the inventory of referential forms in the target language (e.g., the availability of null objects or clitic pronouns), and the knowledge of semantic-pragmatic knowledge of the properties that constrain the distribution of these forms (Serratrice and Hervé 2015). Additionally, cognitive abilities modulate children's performance in reference encoding (De Cat 2015).

The acquisition of referential expressions by monolingual children has been the subject of a substantial body of research, because it contributes to our understanding of the linguistic constraints that shape referential choice, how they emerge and in which order and, importantly, how cross-linguistic differences modulate the development of this domain (Serratrice and Allen 2015). Research on the acquisition of referential expressions in bilingual contexts has enriched this demand, mainly by adding a focus on language pairs that differ with respect to the inventory of referential forms (e.g., displaying, or not, null objects) and to its discourse-appropriated distribution (Pérez-Leroux et al. 2017). Previous research has observed that bilingual children acquiring a clitic language may show an extended 
null object stage (e.g., Pirvulescu et al. 2014) and that they may also use pragmatically inadequate noun phrase objects for a longer period than monolingual children. Müller and Hulk (2001), for instance, attributed the higher number of target-deviant null objects produced by bilingual children acquiring a Germanic (Dutch, German) and a Romance non-null object language (Italian, French) to the influence of Topic-Drop in the Germanic contact language. Serratrice (2007) found that English-Italian bilingual children use a greater number of full nouns instead of clitics in Italian in contexts of referent maintenance. The author concluded that the children may avoid clitics because of their complexity.

Overall, research on object expression has shown that reference encoding constitutes a locus of vulnerability in bilingual language development. However, most research has focused on linguistic trajectories in the pre-school age. There are in general only few studies investigating the linguistic competence of bilingual primary school children (see Tomaz et al. forthcoming, for a recent study on Portuguese-French). This age is of particular interest-especially for child heritage speakers (HSs) and with respect to complex phenomena which are generally acquired late-because a dominance shift from the HL (the home language) to the environmental language, typically the school language, takes place at this age (Flores 2015). This may have an effect on the linguistic development of properties of the HL stabilized at this age and lead to a different path compared to monolingual development (Polinsky and Scontras forthcoming). The present study attempts to address this question by analyzing two school-aged bilingual populations from a cross-language perspective. The HLs under investigation display an identical inventory of direct object forms (null objects, clitic pronouns and full NPs), are modulated by similar pragmatic and semantic constraints (accessibility and animacy), and are in contact with the same majority language. Therefore, our guiding research question is whether the two HL groups perform similarly when encoding referential expressions.

\section{Types of Direct Objects in Polish and European Portuguese}

Comparing the acquisition of objects in monolingual and bilingual Polish and EP is interesting because both languages are typologically similar in the domain of object realization. Both languages dispose of clitics and null objects. Overall, Polish and EP make use of the following types of direct objects: NP objects, clitics, and null objects:

Polish:

1. a. Jan zjadł loda. Full noun PHRASE

Jan ate ice cream.

'Jan ate ice cream.'

b. Jan zjadł go. Clitic

Jan ate it $\mathrm{CL}_{\mathrm{C}}$

'Jan ate it.'

c. Zjadł ø. Null овJect

ate

'He ate it.' ～(cf. Sopata 2016)

EP:

2. a. Os empregados iam buscar os bolos.

FULL NOUN PHRASE OBJECT

the employees went pick up the cakes

'The employees went to pick up the cakes.'

b. [Porque eles também levam os filhos para os colégios de manhã] CLitic

[Because they also take the children to the school in the morning]

E vão buscá-los à noite.

and go pick up-them at night

'And they pick them up in the evening.'

c. [Eles têm o seu carrinhos.] Null object

[They have their car(s).] 
Ela vem buscar Ø e pronto e nós lá vamos.

she goes pick up (it) and prompt and we there go

'She picks it up an there we go!' (examples from the PSFB corpus, Barbosa 2015)

The occurrence of null objects is syntactically and pragmatically constrained. According to Raposo (2004), the null object in EP is an empty determiner embedding a null pronoun, pro. The content of pro is identified by moving it to a position close to its antecedent Determiner Phrase (DP) (Kato and Raposo 2005):

3. (esse livro) [FP pro +F [TP eu só encontrei [DP D $t$ ] na FNAC]]

this book I only found $\varnothing$ at-the FNAC

In a similar vein, Sigurðsson (2011) argues that null objects are linked to a sentence peripheral position and, in turn, related to a referent in the discursive context:

4.

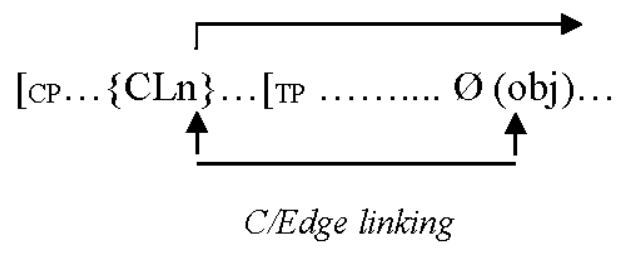

The choice between different referential expressions depends on (a) the degree of accessibility of the discourse referent (cf. Ariel 1985, 1991) and (b) the referential properties of the referent. Definite noun phrases, as opposed to pronouns, refer to less accessible referents which are distant in the discourse, less salient or prominent (e.g., objects rather than subjects), and more ambiguous (e.g., because of intervening NPs). Pronouns mostly occur within the closest distance (the same or a previous sentence), more salient or prominent referents and are preferred if no intervening NPs occur. The more accessible the referent, the more reduced expressions can be used because a highly accessible referent can easily be retrieved from memory and be realized as a null object. Concerning the referential properties of objects, more referential (non-propositional, animate, specific) referents are more likely to be realized by a clitic (Cyrino et al. 2000).

\section{Previous Research on L1 Acquisition of Direct Objects in EP and Polish}

We know that in the course of L1 acquisition young children go through a null object stage where they omit object referents, independent of their target language being a null object language or not (cf. Pérez-Leroux et al. 2017, for an overview). We also know from previous research that for children acquiring EP and Polish, the acquisition of the correct distribution of null and overt objects takes much longer than in other languages and the rate of (illicit) omissions is much higher until later stages of development (cf. Costa and Lobo 2007, 2009; Sopata 2016; Varlokosta et al. 2016). In this section, we will summarize the results of previous studies on monolingual acquisition of the EP and Polish pronoun systems, which used the same experiment as in the present study (Flores et al. submitted; Sopata 2016). This will allow us to discuss the results of the two bilingual groups by comparing them with monolingual EP and Polish children, in addition to making inter-group comparisons.

Flores et al. (submitted) tested 41 Portuguese children from the age of three to nine years (45 to 116 months; mean $=67.9$; SD: 19.5). As in the present study, children were required to answer a question targeting an object referent which (i) was inanimate and was mentioned in the narrative context but not in the question (thus, it was inanimate and not immediately accessible); (ii) was inanimate and was mentioned in the narrative context and in the question (so it was inanimate and immediately accessible); (iii) was animate and was mentioned in the narrative context and in the question (animate and immediately accessible). The results of a generalized linear mixed model showed that the children's 
age and these three different conditions significantly predicted the type of object that was used (either a null object, a clitic pronoun, or a full NP) when answering the question.

When looking at the different test conditions, the results indicated that EP children from the age of four to six years predominantly resort to the use of null objects in all contexts, as shown by other studies on L1 acquisition of EP (Costa and Lobo 2007). By the age of six years, EP children start to distinguish between immediately and not immediately accessible referents, and there is an evident tendency for the children to continuously decrease the omission of objects after this age. From the age of eight to ten years, children clearly favor the use of NPs (68.8\%) in inanimate, non-accessible contexts, and they use around $20 \%$ of clitic pronouns. When the referent is immediately accessible, the rate of null objects decreases to $29.4 \%$ in eight- to ten-year old children, while the rate of clitics is very high (62.7\%). Importantly, the overall use of NPs is reduced in all child groups (4.3-11.3\%) in contexts with immediately accessible object referents. Furthermore, the data show that up to six years of age, EP children are not sensitive to animacy effects, but this sensitivity emerges between the ages of eight and ten years. In this age span, children use only $6.5 \%$ null object structures with immediately accessible animate referents (against $29.4 \%$ inanimate ones). Overall, this study confirmed that the production of different types of direct objects, which is regulated by the factors accessibility and animacy, is stabilized in primary school age in the acquisition of EP. In pre-school age, children still overuse null objects in pragmatically inadequate contexts.

Regarding Polish, the results are very similar, as shown in the studies by Mykhaylyk and Sopata (2016), Sopata (2016), and Sopata et al. (in preparation). Sopata (2016) tested 48 children aged from three to six and showed that young Polish children use a high number of null objects in contexts in which they are not allowed to in adult language. Three-year-olds use $89 \%$ null objects in contexts with immediately accessible inanimate object referents, and $68.4 \%$ in contexts when the inanimate referent is not immediately accessible. The rate of clitics is low in both conditions $(9.9 \%$ in accessible and $14.5 \%$ in non-accessible contexts). The results for four-year-olds and five-year-olds showed a similar pattern. At the age of four years, Polish children produce $62.2 \%$ null objects in accessible contexts and $43.9 \%$ in not immediately accessible contexts. Five-year-olds use $62.2 \%$ null objects in contexts with an immediately accessible referent and $45.5 \%$ in contexts with no immediately accessible object referent. By the age of six years, Polish children obviously distinguish between immediately and not immediately accessible referents. They use $42.2 \%$ null objects in accessible contexts. When the inanimate referent is not immediately accessible, the rate of null objects decreases to $7.5 \%$ in 6-year-old children. From the age of eight to nine years, children use only $2.8 \%$ null objects in not accessible contexts (against $86.1 \%$ NPs and $11.1 \%$ clitics in this condition) and $5.7 \%$ null objects in accessible contexts (against 5.7\% NPs and $88.6 \%$ clitics in this condition) (Sopata et al. in preparation).

Furthermore, Polish data resembles EP data also in children's sensitivity to the animacy factor. Mykhaylyk and Sopata (2016) have shown that children at the age of three prefer null objects for both inanimate $(89 \%$ null objects against $10 \%$ of clitics and $1 \%$ of NPs for inanimate referents) and animate referents ( $82 \%$ null objects against $18 \%$ of clitics and $0 \%$ of NPs for animate referents). Six-year-olds start to distinguish between animate and inanimate referents and produce only $24 \%$ null objects with immediately accessible animate referents (against $42 \%$ inanimate ones). By the age of eight-nine years, Polish children no longer use null objects for immediately accessible animate referents (they use $97.2 \%$ clitics and 2.8\% NPs in this condition) (Sopata et al. in preparation).

Sopata (2016) argues that this prolonged stage in the L1 acquisition of Polish is related to the fact that referential definite null objects have to be linked with C/edge linkers that are valued in relation to prior discourse and pragmatic context (Sigurðsson 2011), which poses a problem for young children. Young Polish children overuse null objects because they assign interpretations to null objects by free context scanning and bypass the syntactic channel for discourse and pragmatic context.

Summing up, monolingual children acquiring EP and Polish seem to take longer than children acquiring other languages to overcome the stage where they produce illicit missing object structures. The acquisition process proceeds in two steps. By the age of six years, children show sensitivity to 
accessibility in both EP and Polish, but it is only from the age of eight-ten that they show sensitivity to animacy. Hence, in both languages, monolingual children acquire the factors conditioning the acquisition of objects in the primary school age. As mentioned in the introduction, the primary school age is of particular interest for child HSs because a dominance shift from the HL to the environmental language, typically the school language, takes place at this age (Flores 2015). The relevant question is, consequently, whether this leads to a differential behavior of bilingual Portuguese-German and Polish-German primary school-aged children with respect to their realization of direct objects in EP and Polish.

\section{The Present Study}

\subsection{Research Questions}

The present study focuses on a comparison between Portuguese-German and Polish-German bilingual primary school children concerning the production of different types of objects in their heritage language. The main research question is whether the two HLs develop in a similar way, because both target languages display identical options for pronoun realization. The analysis is twofold. We start by comparing the performance of the two groups of bilingual children based on two main aspects which characterize the distribution of different types of objects in the two HLs, namely, the familiarity/accessibility and animacy of the object referent.

The first three research questions are the following:

1. Is there a difference between Portuguese-German and Polish-German bilingual children living in Germany or do they behave in a similar way, since their HLs display a similar system of direct object expression?

2. Do bilingual Portuguese-German and Polish-German children react to accessibility in terms of familiarity in EP/Polish?

3. Do bilingual Portuguese-German and Polish-German children distinguish between animate and inanimate referents in Polish/EP?

In a second step, we compare the results of the bilingual children to results obtained in previous studies on monolingual EP and Polish children (see Section 3) in order to find out whether bilinguals differ from age-matched monolinguals concerning the production of different types of objects. The comparison allows us to formulate two additional research questions:

4. Do bilingual children during the ages of 6-10 years differ from monolingual children w.r.t. object production? More precisely: Do bilinguals overuse null objects, clitics, or full NPs?

5. If bilinguals show an overuse in comparison to monolinguals, can this be explained by means of a cross-linguistic influence from German?

\subsection{Participants}

Two groups of bilingual children from the age of six to ten years participated in this study. The first group includes 27 children from Portuguese families who grew up with German as their environmental language and EP as their heritage language (mean age $=8.3 ; \mathrm{DP}=1.33$ ). The second group is composed of 22 children from Polish families living in Germany who are HSs of Polish (mean age $=7.8$; DP $=$ 1.27).

The children were recruited through the HL courses offered to Portuguese and Polish-descendant children in Germany or through cultural associations. They were tested individually in a classroom or at the children's homes. Prior to testing, parents signed the participation consent and filled out a detailed background questionnaire. The questionnaire focused on sociolinguistic and biographical data, such as the children's age of onset of bilingualism, the languages spoken with parents, siblings, 
other family members, and friends, visits to the country of origin, and enrollment in HL courses. Additionally, information about the parents' sociolinguistic background was gathered. ${ }^{1}$

The data gathered in the questionnaires point to a similar background of both language groups regarding the type of bilingualism (simultaneous or successive learners of German), the languages spoken at home (either only the HL or the HL and German) and their enrollment in HL classes (some attend, some do not attend). Quantification includes an input index, based on the amount of HL spoken by each member of the household in interaction with the child (siblings younger than four years old were disregarded), which can range up to $100 \%$ if all family members use only the HL in interaction with the child. This index ranges from 43.8 to 100 (mean $=78.3$; DP $=17$ ) in the Portuguese group and from 20 to 100 in the Polish group (mean $=63.9 ; \mathrm{DP}=25.6$ ). This means that in both groups we find variations with respect to the use of the HL within the nuclear family. Both groups include families where the HL is spoken in parallel to German; in others, only the HL is spoken. In order to take into account the chronological age at testing, the age of onset of bilingualism (AoA), and the enrollment in HL classes, we calculate a further index for cumulative input, where the input index is multiplied by the chronological age. The resulting index is multiplied by 0.8 in the case of simultaneous children and, again, by 0.8 for children who never attended a HL class (this value was set to 1 for successive children, for children who acquired German after age three, and for children who had at least one year of HL instruction). The formula for cumulative input is 'Input index * Age * $0.8(\mathrm{sim}) * 0.8$ (no $\mathrm{HL})^{\prime}$. The resulting cumulative input index ranges from 19.2 to $91.7($ mean $=53.3$; DP $=22)$ for the Portuguese HL group and from 20.2 to 80 (mean = 39.2; DP = 19.6) for the Polish group (see Table 1 for an overview of all variables). Thus, the Portuguese group shows a higher index of cumulative input than the Polish group. A Mann-Whitney test indicates that this difference is statistically significant $(\mathrm{U}$ $=492.48, p<0.001$ ).

Table 1. Participants.

\begin{tabular}{|c|c|c|c|}
\hline & & $\begin{array}{l}\text { Portuguese-German } \\
\qquad(\mathrm{N}=23)\end{array}$ & $\begin{array}{l}\text { Polish-German } \\
\quad(\mathrm{N}=21)\end{array}$ \\
\hline Age: mean (DP) & & $8.3(\mathrm{DP}=1.33)$ & $7.8(\mathrm{DP}=1.27)$ \\
\hline \multirow{2}{*}{ AoA German } & $\operatorname{sim}$ & 17 & 10 \\
\hline & succ & 6 & 11 \\
\hline \multirow{2}{*}{ HL class } & yes & 10 & 8 \\
\hline & no & 13 & 13 \\
\hline \multirow{2}{*}{ Input at home } & mean (DP) & $78.3(17.0)$ & $63.9(25.6)$ \\
\hline & range & $43.8-100$ & 20-100 \\
\hline \multirow{2}{*}{ Cumulative input } & mean (DP) & $53.3(22.0)$ & $39.2(19.6)$ \\
\hline & range & $19.2-91.7$ & $10.20-80$ \\
\hline
\end{tabular}

All families gave their informed consent for inclusion before they participated in the study. The study was conducted in accordance with the Declaration of Helsinki, and the protocol was approved by the Ethics Committee for Research in Social and Human Sciences of the University of Minho on 1 July 2019 (CEICSH 044/2019).

\subsection{Method}

For data collection, we adapted the elicited production task used by Mykhaylyk and Sopata (2016), Sopata (2016), and Mykhaylyk and Ytterstad (2017) by collapsing the conditions tested in two separate

1 In the Polish group, one questionnaire was not completely filled out; in the Portuguese group, four parents did not answer all questions. These children were included in the testing session, but their missing sociolinguistic data were coded as missing data. 
experiments into one experiment only and by further translating it into Portuguese. The experiment is designed to elicit answers to a series of questions, in which the participants has to use direct objects. The questions refer to a story that the experimenter tells by means of several sequences of pictures displayed on a computer screen (see one picture set in Figure 1). All sequences include an explicit mention of a possible discourse antecedent for the target direct object, which can be seen in the picture. This means that the referent has been previously mentioned, is visually present, and is in the focus of joint attention (see Hughes and Allen 2013, 2015 for a discussion of these factors).

The procedure is as follows: Each picture sequence is introduced by a short narrative where a boy, called João/Peter, is involved in an act (e.g., picking a pear from a pear tree). A question about this narrative sequence follows which contains, or does not contain, the referent of the direct object. In their answer, the participants have to use the direct object (see Example 5). ${ }^{2}$

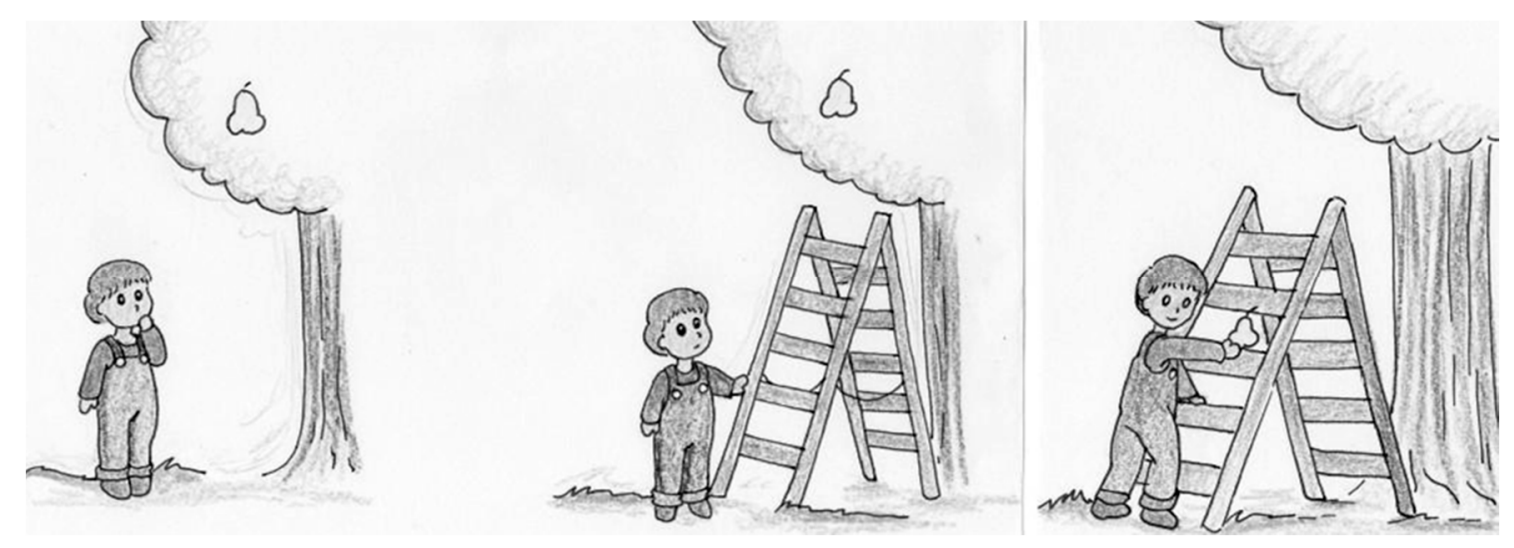

Figure 1. Picture sequence.

5. Context given: In the garden of the grandmother, there was a pear tree with only one pear and a ladder next to the tree. João/Peter wanted to eat this pear.
Question:
O que fez o João?
(EP VERSION)
what did the João
Co Piotruś zrobił?
(Polish version)
what Peter did
'What did João/Peter do?'
Expected Answer: (Ele) apanhou a pera. [NP]
(EP VERSION)
(On) zerwał gruszkę.
(POLISH Version)
(he) picked the pear
'He picked the pear.'

The experiment comprises three test conditions that differ with respect to the accessibility and the animacy of the target object's referent. In the first condition, the discourse referent, which is an inanimate entity, is mentioned in the previous context but not in the question, i.e., it is not immediately accessible. In this case, the participant is expected to use an NP to refer to the object referent (see Example 5). The second condition differs from the first one because the inanimate discourse referent is mentioned in the question. It is expected that the previous mention in the question makes the referent more accessible and prompts the use of a (clitic or null) pronoun (see Example 6).

6. Context given: João/Peter was playing in the garden when he saw a beautiful flower. He thought that his mother would like to see the flower in a vase.

2 If the child did not understand the question, we repeated it. If again she/he did not answer (which happened rarely), we proceeded to the next context and did not count the answer. 


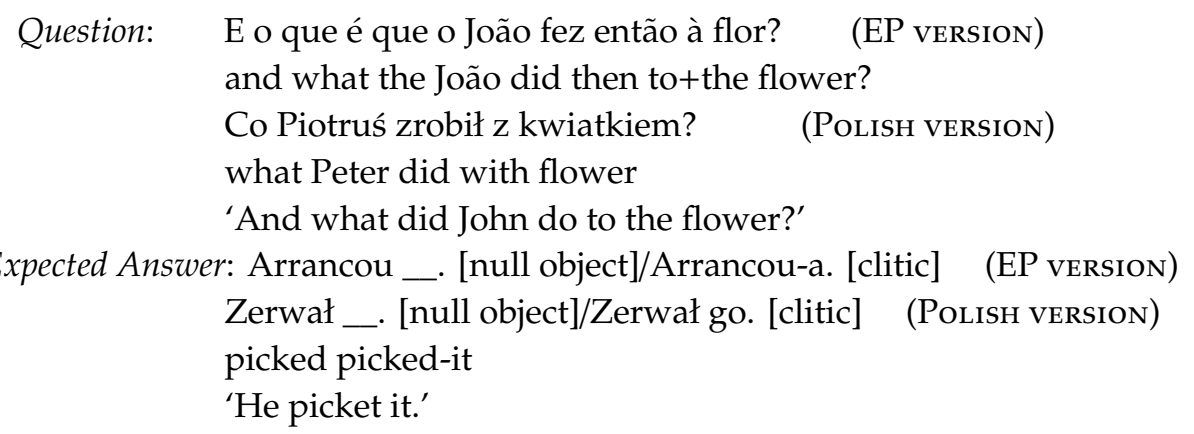

The third condition differs from the second one with respect to animacy, i.e., the object, which is mentioned in the previous question, is animate (see Example 7). In this case, we expect a more pronounced tendency to use the clitic pronoun, because null objects are less likely to occur in animate contexts (Rinke et al. 2018).

7. Context given: On his way to school João/Peter passed to school mates, who wanted to peek into his bag, but he did not let them.

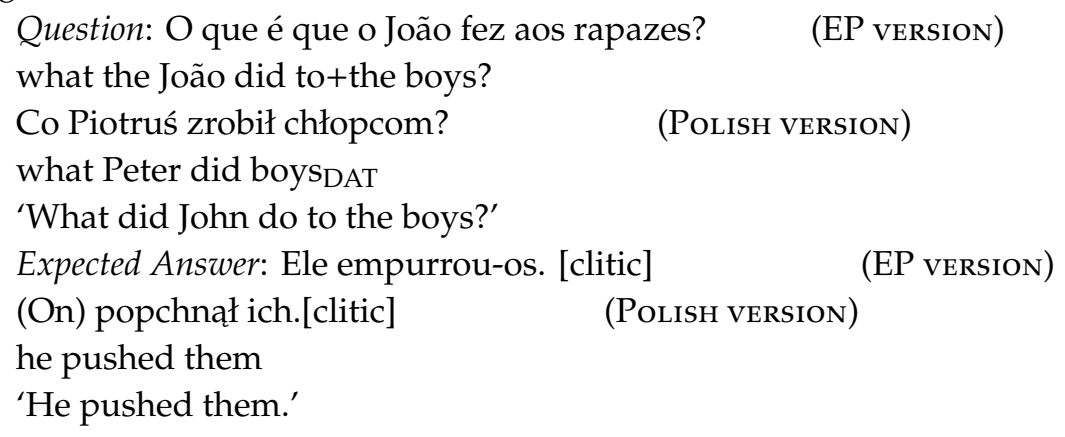

Note that in both languages, EP and Polish, the second condition is the context where both null objects and clitic pronouns are freely exchangeable, whereas, in the third condition, animacy may restrict the choice for a silent object and, in the first condition, the lower accessibility triggers the use of an NP. Table 2 presents an overview of the three test conditions.

Table 2. Test conditions.

\begin{tabular}{ccccc}
\hline Condition & Description & $\begin{array}{c}\text { Immediately } \\
\text { Present in the } \\
\text { Question }\end{array}$ & Animate & No. of Items \\
\hline Condition 1: NIA & $\begin{array}{c}\text { the inanimate } \\
\text { referent is not } \\
\text { immediately } \\
\text { accessible }\end{array}$ & - & - & 6 \\
\hline $\begin{array}{c}\text { Condition 2: IA } \\
\text { inanimate }\end{array}$ & $\begin{array}{c}\text { the inanimate } \\
\text { referent is } \\
\text { immediately } \\
\text { accessible }\end{array}$ & + & \\
\hline $\begin{array}{c}\text { Condition 3: IA } \\
\text { animate }\end{array}$ & $\begin{array}{c}\text { the animate } \\
\text { referent is } \\
\text { immediately } \\
\text { accessible }\end{array}$ & + \\
\hline
\end{tabular}

The sentences were presented in a pseudo-randomized order. Participants responded to two prior training items. The words in immediately preceding questions were carefully chosen with respect to their morphological and syntactic properties. The same subject was used in all items and verb forms were in the past tense in both languages. 


\section{Results}

The two bilingual groups produced a total of 665 valid answers (out of 882), which amounts to $75.4 \%$ of relevant items ( $76.2 \%$ in the Portuguese group and $74.1 \%$ in the Polish group). Items were excluded from analysis when the participant did not answer (very rarely) or gave an answer without the target verb or a lexical equivalent.

For the statistical analysis, we use a generalized linear mixed model (GLMM) with a multinominal dependent variable, executed in SPSS 23. The child's 'answer' is the dependent variable with three values (null, clitic, NP; null is coded as the reference value). As fixed effects, the model includes 'condition' (not immediately accessible (NIA), immediately accessible inanimate (IA in), immediately accessible animate (IA an)), 'group' (Portuguese-German, Polish-German) and 'cumulative input' (as continuous variable), and the random intercepts 'participants' and 'items'. Note that the cumulative input index combines the variables 'AoA of German', 'HL instruction', 'chronological age', and 'input at home'. In fact, several Spearman correlation tests showed that these individual variables are correlated (see correlation matrix of fixed factors for EP-German bilinguals in Table S1 and correlation matrix of fixed factors for Polish-German bilinguals in Table S2 in the Supplementary Files). To avoid effects of collinearity, they were excluded from the model and only the cumulative input index is used to test for extra-linguistic effects.

The model shows a predictive effect of condition $(p<0.0001)$ and a marginal effect of cumulative input $(p=0.056)$, but no group effect $(p=0.178)$ (see Table 3$)$.

Table 3. Generalized linear mixed model (GLMM) results, all test conditions included.

\begin{tabular}{lcccc}
\hline & F & gl1 & g12 & Sig. \\
\hline corrected model & 6.910 & 8 & 638 & 0.000 \\
condition & 11.594 & 4 & 638 & 0.000 \\
group & 1.730 & 2 & 638 & 0.178 \\
cum. input & 2.887 & 2 & 638 & 0.056 \\
\hline
\end{tabular}

These results indicate that the children's use of different types of objects is significantly modulated by the test condition and by their degree of input to their HL. This result further demonstrates that the two bilingual groups do not differ, i.e., Portuguese and Polish heritage children show the same linguistic behavior in the domain of object choice in their home language.

Now let us look at the bilingual children's sensitivity to the factors accessibility and animacy. Table 4 provides an overview of the results of the two groups in the three test conditions.

Table 4. Distribution of object forms per condition and per group (in \%).

\begin{tabular}{lccccccccc}
\hline & \multicolumn{1}{c}{ NIA } & \multicolumn{3}{c}{ IA Inanimate } & \multicolumn{3}{c}{ IA Animate } \\
\hline & NP & clitic & null & NP & clitic & null & NP & clitic & null \\
\hline Portuguese & 63.4 & 15.9 & 20.7 & 22.9 & 43.9 & 33.1 & 18.2 & 56.2 & 25.5 \\
Polish & 54.9 & 18.6 & 26.5 & 12.1 & 40.2 & 47.7 & 5.1 & 64.3 & 30.6 \\
\hline
\end{tabular}

As explained above, the NIA condition differs from the IA conditions in that the referent is not immediately accessible in the preceding question, but it is mentioned in the narrative. It was expected that the speakers would produce more full noun phrases than (clitic/null) pronouns in this condition. Results show that this is indeed the case in both groups of children. The Portuguese HSs produced $63.4 \%$ and the Polish group $54.9 \%$ of target-like definite NPs. Clitic pronouns and null objects also occur to some extent in this condition, with more object omissions than clitics in both languages.

In the IA condition, the inanimate referent of the target object is mentioned in the prior discourse and also appears in the immediately preceding question. Therefore, a higher amount of clitics and null objects and a lower amount of NPs than in the first condition were expected. The results of the 
bilingual children in this second condition shows that, as expected, they predominantly produce null objects and clitics and much fewer NPs than in the NIA condition. The rate of clitic objects amounts to $43.9 \%$ in the Portuguese and to $40.2 \%$ in the Polish group. The rate of NPs decreases to $22.9 \%$ and $12.1 \%$, respectively, in the Portuguese and Polish groups. This means that the Portuguese group produces more NPs than the Polish group. Furthermore, it is interesting to note that the Polish HSs produce more null object sentences than the Portuguese HSs (47.7\% against $33.1 \%$ ).

The performance reported so far clearly indicates that bilingual children of both language groups distinguish between not immediately accessible and immediately accessible objects.

In the third condition, the referent is accessible, as in the second condition, but it is animate. Animacy, in combination with accessibility, favors the use of an overt clitic. It was expected, thus, that the children would produce fewer NPs than in the first condition (NIA) and fewer null objects than in the second condition (IA inanimate). The results obtained for this third condition show that children are also sensitive to the referential properties of the referent. Both groups of bilingual children produce a higher amount of clitics and fewer null objects than in the IA-inanimate condition.

A second GLMM, including only the IA conditions, analyzes specifically the effect of animacy. The dependent variable is 'answer' (null as reference), the fixed factors are 'group' and 'condition', and the random intercepts are 'subjects' and 'items'.

The results (see Table 5) show that 'condition' significantly predicts the children's answer when the null object option is contrasted with the clitic pronoun option $(p=0.044)$. This means that in both groups, animacy indeed predicts the choice between null and clitic pronoun constructions. When the null object option is opposed to the NP option, there is a marginal group effect $(p=0.053)$, i.e., the two groups differ marginally with respect to the use of NPs.

Table 5. Generalized linear mixed model (GLMM) results for immediately accessible (IA) conditions.

\begin{tabular}{lcccc}
\hline & Coefficient & Error & t & Sig. \\
\hline $\begin{array}{l}\text { Null vs. Clitics } \\
\text { Condition InAn: }\end{array}$ & -0.419 & 0.2073 & -2.020 & 0.044 \\
\hline $\begin{array}{l}\text { Null vs. NPs } \\
\text { Group Bil_PTG }\end{array}$ & 0.488 & 0.2513 & 1.943 & 0.053 \\
\hline
\end{tabular}

\section{Discussion and Conclusions}

We will start by discussing our first research question, which focuses on the comparison between Polish-German and Portuguese-German bilingual children living in Germany. Overall, the results reveal that both bilingual groups perform in a similar way concerning the production of different types of objects. They display all three options of object realization, i.e., null objects, clitic pronouns, and full NPs, and use them in a similar way and in accordance with the pragmatic and semantic constraints of the tested contexts. The GLMM confirms that the fixed factor 'group' is not a predictive variable. We conclude that similarities in the underlying grammatical system of the target languages result in similar developmental pathways in heritage bilinguals with different HLs.

A further relevant finding, which confirm results from many other studies (e.g., Unsworth 2014), is related to the role of the amount of input in bilingual language development. The GLMM points to a predictive (even though marginal) effect of the input index, which comprises children's chronological age, their AoA of bilingualism, the frequency of use of the HL within the family, and their enrollment in HL classes. This means that the accumulated amount of contact with the HL modulates the development of the HL system in the domain of direct object expression. Similar effects of amount of input on the grammatical development of home languages have been found in many other domains (Flores et al. 2017b for mood choice in EP; Gathercole and Thomas 2009 for grammatical gender in Welsh; Thordardottir 2015, for English and French verbal morphology). 
The overall results of this study reveal that the relevant predictor for participants' object choice is the test condition. As expected, both groups of HSs distinguish between immediately and not immediately accessible referents. When the referent is mentioned in the discursive context, but is not the target of the immediately preceding question, Portuguese and Polish heritage children predominantly choose a full NP to mention the object referent. This contrasts with immediately accessible referents, mentioned in the question. In these contexts, children use fewer NPs and show a preference for a pronominal structure (null or clitic object). This shows that bilingual children are sensitive to accessibility in terms of familiarity of the referent. As a response to our second research question, we conclude that both bilingual groups have acquired the pragmatic constraints regulating the choice between NPs and pronouns. This confirms previous findings on bilingual child populations, e.g., Paradis and Navarro's (2003) study on subject realization in Spanish-English bilingual children.

The third research question relates to the semantic constraints of object choice, namely whether bilingual children's pronominal choice is modulated by animacy of the referents in their HL. The second GLMM indicates a predictive effect of animacy in both groups of children. This shows that bilingual children are not only sensitive to accessibility but also to the animacy of the referent. As expected, they produce more null objects with inanimate referents and more clitic objects in the animate condition. In a recent study on object realization by EP and BP child HSs living in France, Tomaz et al. (forthcoming) come to similar conclusions regarding animacy effects in the expression of object pronouns in the HL. Using two elicited production tasks, the authors show that the pattern of development found in their bilingual groups is very similar to the one observed in the monolingual control group. Both groups show higher rates of omission with inanimate antecedents than with animate ones.

In order to answer the fourth and fifth research questions regarding the comparison with monolinguals, we turn to the results from Flores et al. (submitted), Sopata (2016), and Mykhaylyk and Sopata (2016) on monolingual EP and Polish children reported in Section 3. If we compare the rate of the different object forms produced by age-matched monolingual and bilingual speakers of EP in not immediately accessible contexts, it becomes clear that both groups of EP-speaking children show a similar tendency of realizing the object as a full NP (bilinguals: $63.4 \%$ of NPs against $15.9 \%$ clitics and $20.7 \%$ null objects vs. monolinguals: $68.8 \%$ NPs against 22.9 clitics and $8.3 \%$ null objects). The situation is similar when comparing age-matched Polish-speaking monolingual and bilingual children. By the age of eight-nine years, Polish monolinguals tend to use full NPs when the referent is not immediately accessible ( $86.1 \%$ NPs against $11 \%$ clitics and $2.8 \%$ null objects in NIA contexts). Similarly, bilingual speakers of Polish prefer to use NPs in the same contexts (54.9\% NPs against $18.6 \%$ clitics and $26.5 \%$ null objects in NIA contexts). The preference for NPs in Polish bilinguals in NIA contexts is weaker than in age-matched monolinguals due to the higher amount of null objects (and also clitics) they produce in this context. Interestingly, Portuguese children also use a higher amount of null objects; however, in their case, this is more at the expense of clitics. The explanation for this disparity may lay in the clitic system of both languages. It is well known that the EP clitic system is very complex, showing variation regarding the form and the placement of clitic pronouns. For example, clitics in EP may assume different forms depending on the phonological context. After a liquid, the clitic a (3rd person accusative feminine) is realized as $l a$ and after a nasal as na. This allomorphy is illustrated in $8 \mathrm{a} / \mathrm{b}$.

8. a. encontrar + -a $>$ encontrá-la

to meet + her

'to meet her'

b. encontraram $+-\mathrm{a}>$ encontraram-na

met + her

'They met her.'

EP clitics do not only assume different forms depending on the phonological context, but also occupy different positions vis-à-vis the verb, its host, depending on the syntactic context. For example, 
in simple subject or verb-initial main clauses, the clitic occurs in an enclitic position, while in subordinate contexts and with negation, among other contexts, the clitic is realized in a proclitic position (see Example 9).

9. a. Vi-a.

'I saw her.'

b. A Maria disse, que a viu.

the Mary said that her saw

'Mary said that she saw her.'

c. Não a vi.

not her saw

'I didn't see her.'

As suggested by Flores et al. (2017a), this complexity may lead Portuguese HSs to avoid the use of clitic pronouns in favorable contexts. Since the Polish clitic system does not show the same phonological and syntactic context sensitivity, it is less complex (see Franks and King 2000) than the EP clitic system. We conclude that, therefore, Polish HSs display less difficulty in using clitic pronouns, even in unfavorable contexts.

In immediately accessible contexts with animate referents (IA animate), bilinguals preferentially produce clitics. This preference in bilingual speakers of Polish $(64.3 \%$ clitics against $5.1 \%$ NPs and $30.6 \%$ null objects) is also attested for age-matched monolinguals $(97.2 \%$ clitics against $2.8 \%$ NPs and $0 \%$ null objects). The same is also true for Portuguese speakers, where bilinguals and monolinguals prefer clitics in immediately accessible animate contexts (bilinguals: $56.2 \%$ clitics against $18.2 \%$ NPs and $25.5 \%$ null objects; monolinguals: $89.1 \%$ clitics against $4.3 \%$ NPs and $6.5 \%$ null objects). Despite the similar tendency of using more clitics in animate contexts, the data show that bilingual Polish and Portuguese children produce a considerably higher amount of null objects in these contexts, compared to their monolingual peers.

Interestingly, bilingual child speakers of EP not only produced more null objects but also more NPs than monolinguals in the conditions with immediately accessible referents: IA inanimate: $22.9 \%$ NPs (EP bilinguals) vs. $7.8 \%$ NPs (EP monolinguals) and IA animate: $18.2 \%$ NPs (EP bilinguals) vs. $4.3 \%$ NPs (EP monolinguals). Because of the higher amount of NPs and null objects in the IA inanimate and animate contexts in bilinguals, the animacy effect is less evident in the bilingual EP group than in monolinguals.

Hence, there are two differences between bilingual and monolingual primary school children acquiring EP and Polish, which call for an explanation: First, the overuse of null objects in both bilingual groups in comparison to monolinguals and, second, the higher amount of NPs in bilingual EP children. We will come back to these differences.

The last research question relates to the role of German as a contact language. Given the fact that German does not have null objects, it is unlikely that bilingual children overuse this option of object realization because of influence from German. As argued by Müller and Hulk (2001), German makes use of the so-called Topic-Drop structure, which could exert influence on the contact language. Topic-Drop refers to the omission of a (subject or object) topic at the sentence-initial position in German. However, it is restricted to colloquial language registers, and the topic may only be omitted in the first position (see Example 10):

10. a. Ich hab' ihn schon gesehen

$\mathrm{I}_{\mathrm{NOM}}$ have him $\mathrm{ACC}_{\text {already seen }}$

'I saw him already'

b. [ ] hab' ihn schon gesehen [ ] = NOM

c. [ ] hab' ich schon gesehen [ ] = ACC

(examples from Bayer et al. 2001, p. 490) 
If we contrast German with EP and Polish, the German structure is more restricted, in syntactic, discursive, and also register-related terms, than the EP/Polish null object structure. Recall that the situation is different from that of the German-French or German-Italian bilinguals investigated in Müller and Hulk (2001) because those children acquire a Romance non-null object language. There is, thus, no valid argument to consider the influence of a more restrictive structure over a less restrictive one. Even if their proposal concerning the influence of Topic-Drop could account for an extended period of omissions in bilinguals, it could not explain the higher proportion of NP objects in bilingual HSs of EP.

We argue against a cross-linguistic influence in these children, at least in terms of a direct impact of the grammar of the contact language on the grammar of the HL. Instead, there is a difference in the rate of acquisition. The two groups of bilingual children appear to show a delay in comparison to monolingual children. If we compare bilinguals acquiring EP to younger monolinguals, we find that monolinguals may also overuse NPs in conditions with accessible referents. In our previous study on monolingual acquisition (Flores et al., submitted), this manifests itself in condition IA animate, where younger bilinguals (aged five-six) realize 10.3\% of full noun phrases. The study by Varlokosta et al. (2016, p. 13) shows a more expressive use of NPs (=DPs) by young children (approx. five years old) acquiring EP (11.9\%) in comparison to all other child groups acquiring a clitic language (see Table 6).

Table 6. Distribution of objects in five-year-olds; table taken from Varlokosta et al. (2016, p. 13).

\begin{tabular}{cccccc}
\hline Language & Clitics (Range; SD) & DPs & Omission & Pronouns & Other \\
\hline Catalan & $98.8(92.0-100 ; 3)$ & 0.4 & 0.0 & 0.0 & 0.8 \\
Croatian & $79.6(33.0-100 ; 18)$ & 5.0 & 6.4 & 1.0 & 7.7 \\
Cypriot Greek & $96.0(83.0-100 ; 5)$ & 0.7 & 0.6 & 0.0 & 2.7 \\
French & $90.0(33.0-100 ; 19)$ & 4.7 & 2.3 & 0.0 & 3.0 \\
Greek & $92.1(67.0-100 ; 10)$ & 2.5 & 0.4 & 4.2 & 0.8 \\
Italian & $92.9(67.0-100 ; 10)$ & 2.5 & 2.5 & 0.8 & 1.3 \\
Polish & $71.0(0.0-100,33)$ & 3.0 & 18.3 & 3.0 & 4.8 \\
Portuguese & $19.3(0.0-75 ; 25)$ & 11.9 & 56.1 & 8.2 & 4.5 \\
Romanian & $90.8(67.0-100 ; 11)$ & 5.4 & 1.3 & 0.0 & 2.5 \\
Serbian & $77.7(42.0-100 ; 14)$ & 6.3 & 6.7 & 2.7 & 6.6 \\
Spanish & $94.2(75.0-100 ; 7)$ & 1.8 & 2.2 & 1.1 & 0.7 \\
\hline
\end{tabular}

The second observation of a higher amount of object omissions in bilinguals can also be confirmed for younger monolinguals. As already mentioned in Section 3, five-year-old Polish monolingual children still use $62 \%$ null objects in the IA inanimate condition (bilinguals $47.7 \%$ null objects) and $47 \%$ null objects in the IA animate condition (bilinguals $30.6 \%$ null objects). Younger monolingual children (five-six years old) acquiring EP use $53.8 \%$ of null objects in condition IA inanimate (bilinguals $33.1 \%$ ) and $46.6 \%$ of object omissions in condition IA animate (bilinguals $25.5 \%$ null objects). In fact, both with respect to Polish and EP as the HL language, bilinguals seem to be in an acquisition stage corresponding to a five- to seven-year-old monolingual.

The question we cannot answer on the basis of our data is whether the differences in production between monolingual and bilingual populations persist or whether they disappear over time. A study by Rinke et al. (2018) on the production of null objects in the spontaneous speech of adult monolingual and bilingual speakers of EP revealed that adult bilinguals still exhibit a less expressed animacy effect than monolinguals. This study also showed that HSs produce more animate null objects than monolinguals. The authors interpreted this finding in terms of a diachronic extension of null objects along a referential scale, as argued by Cyrino et al. (2000) for the diachrony of Brazilian Portuguese. This may be an indicator that bilingual speakers tend to maintain higher rates of silent objects in their speech into adulthood. Note that this cannot be taken as evidence for the assumption that the external discourse interface as such represents a vulnerable domain for bilingual speakers (cf. Sorace and 
Serratrice 2009) because the bilingual children in the present study show early sensitivity to discourse conditions (i.e., to accessibility of the referent).

Differences between Polish and Portuguese can be related to a general tendency to avoid the use of clitics in EP but not in Polish. This tendency can be observed in Varlokosta et al.'s (2016) investigation on five-year-old monolingual children acquiring clitic languages. As can be seen in Table 6, the EP children in this study produced only $19.3 \%$ of clitic objects, an extremely low amount in comparison to age-matched children acquiring other clitic languages including Polish (71.0\% clitics). The avoidance (and late acquisition) of clitics in EP has two consequences in development: First, an overuse of null objects, and second, an overuse of NPs in immediately accessible contexts.

Overall, the present study shows that bilingual HSs of Polish and Portuguese living in Germany acquire the options of object realization in their HL in a similar fashion because of the similarities with respect to the relevant properties in the target languages and despite intensive contact with German. In some respects, they resemble younger monolinguals pointing to a slightly protracted development, which may be explained by language-internal properties.

Supplementary Materials: The following are available online at http://www.mdpi.com/2226-471X/4/3/53/s1: Table S1, Correlation matrix of fixed factors (EP-German bilinguals); Table S2, Correlation matrix of fixed factors (Polish-German bilinguals).

Author Contributions: All three authors have substantially contributed to this article to the same extent. Polish and Polish-German bilingual data: A.S., Portuguese data: C.F., Portuguese-German bilingual data: E.R., data analysis and discussion: All three authors.

Funding: The research was partially funded by the Portuguese Fundação para a Ciência e Tecnologia (Reference: > UID/ELT/00305/2019) and by a grant from the National Science Centre, Poland, 2014/15/G/HS6/04521.

Acknowledgments: We are grateful to all Portuguese and Polish families, HL teachers and Portuguese and Polish cultural associations in Germany who made data collection possible. Without them, this study would not have been possible.

Conflicts of Interest: The authors declare no conflict of interest.

\section{References}

Ariel, Mira. 1985. Givenness Marking. Ph.D. Thesis, Tel-Aviv University, Tel-Aviv, Israel.

Ariel, Mira. 1991. The function of accessibility in a theory of grammar. Journal of Pragmatics 16: 443-63. [CrossRef]

Barbosa, Pilar, coord. 2015. Perfil Sociolinguístico da Fala Bracarense (PSFB). Braga: Universidade do Minho, Available online: https://sites.google.com/site/projectofalabracarense/ (accessed on 2 February 2019).

Bayer, Josef, Markus Bader, and Michael Meng. 2001. Morphological underspecification meets oblique case: Syntactic and processing effects in German. Lingua 111: 465-514. [CrossRef]

Costa, João, and Maria Lobo. 2007. Clitic omission, null objects or both in the acquisition of European Portuguese? In Romance Languages and Linguistic Theory. Edited by Sergio Baauw, Frank Drijkoningen and Manuela Pinto. Amsterdam and Philadelphia: John Benjamins, pp. 59-71.

Costa, João, and Maria Lobo. 2009. Clitic omission in the acquisition of European Portuguese: Data from comprehension. In Minimalist Inquiries into Child Language Acquisition. Case Studies across Portuguese. Edited by Acrísio Pires and Jason Rothman. Berlin and New York: Mouton de Gruyter, pp. 63-84.

Cyrino, Sônia, Maria Eugênia Duarte, and Mary A. Kato. 2000. Visible subjects and invisible clitics in Brazilian Portuguese. In Brazilian Portuguese and the Null Subject Parameter. Edited by Mary A. Kato, Esmeralda V. Negrão and Frankfurt am Main. Vervuert and Madrid: Iberoamericana, pp. 55-73.

De Cat, Cécile. 2015. The cognitive underpinnings of referential abilities. In The Acquisition of Reference. Edited by Ludovica Serratrice and Shanley E. M. Allen. Amsterdam: John Benjamins, pp. 263-83.

Flores, Cristina. 2015. Understanding heritage language acquisition. Some contributions from the research on heritage speakers of European Portuguese. Lingua 164: 251-65. [CrossRef]

Flores, Cristina, Esther Rinke, and Cecília Azevedo. 2017a. Object realization across generations. A closer look on the spontaneous speech of Portuguese first and second generation migrants. In Complexity in Acquisition. Edited by Elisa Domenico. Tyne, UK: Cambridge Scholars, pp. 178-205. 
Flores, Cristina, Ana Lúcia, Santos, Alice Jesus, and Rui Marques. 2017b. Age and input effects in the acquisition of mood in Heritage Portuguese. Journal of Child Language 44: 795-828. [CrossRef] [PubMed]

Flores, Cristina, Esther Rinke, and Aldona Sopata. submitted. Acquiring the distribution of null and overt direct objects in L1 Portuguese. Language Acquisition.

Gathercole, Virginia, and Enlii Thomas. 2009. Bilingual first-language development: Dominant language takeover, threatened minority language take-up. Bilingualism: Language and Cognition 12: 213-37. [CrossRef]

Franks, Steven, and Tracy Holloway King. 2000. A Handbook of Slavic Clitics. Oxford: Oxford University Press.

Hughes, Mary, and Shanley E. M. Allen. 2013. The effect of individual discourse-pragmatic features on referential choice in child English. Journal of Pragmatics 56: 15-30. [CrossRef]

Hughes, Mary, and Shanley E. M. Allen. 2015. The incremental effect of discourse-pragmatic sensitivity on referential choice in the acquisition of a first language. Lingua 155: 43-61. [CrossRef]

Müller, Natascha, and Aafke Hulk. 2001. Crosslinguistic influence in bilingual language acquisition: Italian and French as recipient languages. Bilingualism: Language and Cognition 4: 1-21. [CrossRef]

Kato, Mary, and Eduardo P. Raposo. 2005. Obje(c)tos e artigos nulos: similaridades e diferenças entre o português europeu e o português brasileiro. In Reflexões Sobre a Sintaxe do Português. Edited by Denilda Moura. Maceió: Edufal, pp. 73-96.

Mykhaylyk, Roksolana, and Aldona Sopata. 2016. Object pronouns, clitics, and omissions in child Polish and Ukrainian. Applied Psycholinguistics 37: 1051-82. [CrossRef]

Mykhaylyk, Roksolana, and Elinor Ytterstad. 2017. Directionality of cross-linguistic influence: Which referring choices do bilingual Ukrainian-English children make? International Journal of Bilingualism 21: 99-121. [CrossRef]

Paradis, Johanne, and Samuel Navarro. 2003. Subject realization and crosslinguistic interference in the bilingual acquisition of Spanish and English: what is the role of the input? Journal of Child Language 30: 371-93. [CrossRef] [PubMed]

Pérez-Leroux, Anna Theresa, Mihaela Pirvulescu, and Yves Roberge. 2017. Direct Objects and Language Acquisition. Cambridge: Cambridge University Press.

Pirvulescu, Mihaela, Ana Theresa Pérez-Leroux, Yves Roberge, Nelleke Strik, and Danielle Thomas. 2014. Bilingual effects: Exploring object omission in pronominal languages. Bilingualism: Language and Cognition 17: 495-510. [CrossRef]

Polinsky, Maria, and Gregory Scontras. forthcoming. Understanding Heritage Languages. Bilingualism: Language and Cognition.

Raposo, Eduardo. 2004. Objectos Nulos e CLLD: Uma Teoria Unificada. Revista da ABRALIN 3: 41-73. [CrossRef]

Rinke, Esther, Cristina Flores, and Pilar Barbosa. 2018. Null objects in the spontaneous speech of monolingual and bilingual speakers of European Portuguese. Probus 30: 93-119. [CrossRef]

Serratrice, Ludovica. 2007. Referential cohesion in the narratives of bilingual English-Italian children and monolingual peers. Journal of Pragmatics 39: 1058-87. [CrossRef]

Serratrice, Ludovica, and Coralie Hervé. 2015. Referential expressions in bilingual acquisition. In The Acquisition of Reference. Edited by Ludovica Serratrice and Shanley E. M. Allen. Amsterdam: John Benjamins, pp. 311-33.

Serratrice, Ludovica, and Shanley Allen. 2015. Introduction: An overview of the acquisition of reference. In The Acquisition of Reference. Edited by Ludovica Serratrice and Shanley E. M. Allen. Amsterdam: John Benjamins, pp. 1-24.

Sigurðsson, Halldór A. 2011. Conditions on argument drop. Linguistic Inquiry 42: 267-304. [CrossRef]

Sopata, Aldona. 2016. Null objects in adult and child Polish: Syntax, discourse and pragmatics. Lingua 183: 86-106. [CrossRef]

Sopata, Aldona, Cristina Flores, and Esther Rinke. The Acquisition of Direct Object by Polish Heritage Bilinguals in Contact with German, Manuscript in preparation.

Sorace, Antonella, and Ludovica Serratrice. 2009. Internal and external interfaces. International Journal of Bilingualism 13: 195-210. [CrossRef]

Thordardottir, Elin. 2015. The relationship between bilingual exposure and morphosyntactic development. International Journal of Speech Language Pathology 17: 97-114. [CrossRef] [PubMed]

Tomaz, Margarida, Maria Lobo, Ana Madeira, Carla Soares-Jesel, and Stéphanie Vaz. forthcoming. Omissão e colocação de clíticos por crianças bilingues Português-Francês. Revista da APL. 
Unsworth, Sharon. 2014. Comparing the role of input in bilingual acquisition across domains. In Input and Experience in Bilingual Development. Edited by Theres Grüter and Johanne Paradis. Amsterdam: John Benjamins, pp. 81-201.

Varlokosta, Spyridoula, Adriana Belletti, João Costa, Naama Friedmann, Anna Gavarró, Kleanthes K. Grohmann, and Kazuko Yatsushiro. 2016. A cross-linguistic study of the acquisition of clitic and pronoun production. Language Acquisition 23: 1-26. [CrossRef] 